Article

\title{
Spatiotemporal Changes in Plasmodium vivax msp142 Haplotypes in Southern Mexico: From the Control to the Pre-Elimination Phase
}

\author{
Alejandro Flores-Alanis ${ }^{1} \mathbb{D}$, Lilia González-Cerón ${ }^{2, * \mathbb{D}}$, Frida Santillán-Valenzuela ${ }^{2}$, Cecilia Ximenez ${ }^{3}$, \\ Marco A. Sandoval-Bautista ${ }^{2}$ and Rene Cerritos ${ }^{4, *}$
}

check for updates

Citation: Flores-Alanis, A.; González-Cerón, L.;

Santillán-Valenzuela, F.; Ximenez, C.; Sandoval-Bautista, M.A.; Cerritos, R. Spatiotemporal Changes in Plasmodium vivax $\mathrm{msp}_{42}$ Haplotypes in Southern Mexico: From the Control to the Pre-Elimination Phase. Microorganisms 2022, 10, 186. https://doi.org/10.3390/ microorganisms10010186

Academic Editor: Graham H. Mitchell

Received: 28 December 2021 Accepted: 11 January 2022 Published: 15 January 2022

Publisher's Note: MDPI stays neutral with regard to jurisdictional claims in published maps and institutional affiliations.

Copyright: (C) 2022 by the authors. Licensee MDPI, Basel, Switzerland. This article is an open access article distributed under the terms and conditions of the Creative Commons Attribution (CC BY) license (https:// creativecommons.org/licenses/by/ $4.0 /)$.
1 Departamento de Microbiología y Parasitología, Facultad de Medicina, Universidad Nacional Autónoma de México (UNAM), Mexico City 04360, Mexico; bioalejandrofa@gmail.com

2 Regional Center for Public Health Research, National Institute of Public Health (INSP), Tapachula 30700, Mexico; fsantill@insp.mx (F.S.-V.); masb@insp.mx (M.A.S.-B.)

3 Unidad de Medicina Experimental, Facultad de Medicina, Universidad Nacional Autónoma de México (UNAM), Mexico City 06720, Mexico; cximenez@unam.mx

4 Centro de Investigación en Políticas, Población y Salud, Facultad de Medicina, Universidad Nacional Autónoma de México (UNAM), Mexico City 04510, Mexico

* Correspondence: lgonzal@insp.mx (L.G.-C.); renecerritos@gmail.com (R.C.)

\begin{abstract}
For 20 years, Plasmodium vivax has been the only prevalent malaria species in Mexico, and cases have declined significantly and continuously. Spatiotemporal genetic studies can be helpful for understanding parasite dynamics and developing strategies to weaken malaria transmission, thus facilitating the elimination of the parasite. The aim of the current contribution was to analyze P. vivax-infected blood samples from patients in southern Mexico during the control (1993-2007) and pre-elimination phases (2008-2011). Nucleotide and haplotype changes in the $p v m s p 1_{42}$ fragment were evaluated over time. The majority of multiple genotype infections occurred in the 1990s, when the 198 single nucleotide sequences exhibited 57 segregating sites, 64 mutations, and 17 haplotypes. Nucleotide and genetic diversity parameters showed subtle fluctuations from across time, in contrast to the reduced haplotype diversity and the increase in the $\mathrm{R}^{2}$ index and Tajima's D value from 2008 to 2011. The haplotype network consisted of four haplogroups, the geographical distribution of which varied slightly over time. Haplogroup-specific B-cell epitopes were predicted. Since only high-frequency and divergent haplotypes persisted, there was a contraction of the parasite population. Given that $84 \%$ of haplotypes were exclusive to Mesoamerica, $P$. vivax flow is likely circumscribed to this region, representing important information for parasite surveillance.
\end{abstract}

Keywords: Plasmodium vivax; merozoite surface protein 1 (42 kD); pvmsp $1_{42}$; haplotype diversity; haplogroups; B-cell epitopes; control and pre-elimination phases; southern Mexico

\section{Introduction}

There are approximately 241 million malaria cases per year worldwide and 627,000 related deaths, according to the estimates of the World Health Organization (WHO) [1]. In Mexico, the number of cases fluctuated between 20,000 and 130,000 per year in the 1980s. In the following decade, the anti-malaria measures of the intensified control programs caused a gradual decrease in cases.

Anti-malarial control measures are implemented when the burden of malaria infection becomes an important public health problem and the slide positivity rate of fever cases is above $5 \%$. The latter rate is a method for analyzing changes in malaria incidence; if it drops below 5\% and certain other requirements are met, a country may enter the pre-elimination phase, which consists of the evaluation and reorientation of anti-malaria policies and strategies with the aim of continually reducing the number of cases [2]. Mexico has remained in the pre-elimination phase since 2007. 
In Mexico, the number of malaria cases had declined to 514 by 2016 [3]. Nevertheless, in 2017 this country reported a 37\% rise in cases-most notably in the states of Chiapas, Chihuahua, and Tabasco. Alarmingly, new cases began to appear in San Luis Potosi in the same year, a state formerly enjoying an absence of malaria transmission $[1,3,4]$.

The multiple mosquito vectors implicit in Plasmodium vivax genetic and haplotype diversity contribute to successful transmission in distinct environments [5]. Such diversity potentially plays an important role in the development of parasite mechanisms for evasion of the vertebrate and invertebrate host immune response (even after the application of vaccines) and for the selection of strains resistant to current drugs [6,7]. Various evolutionary forces act on genes that code for blood-stage antigens, resulting in high polymorphism and parasite diversity. Thus, it is necessary to distinguish between the different species of parasites and trace their haplotypes [8]. Additionally, this information is essential for designing effective vaccines and surveillance strategies [9]. For countries moving to the elimination phase, therefore, a key strategy is the use of genetic studies with polymorphic markers to understand transmission dynamics. They provide evidence of the weakening of parasite transmission when the number of cases is diminishing, and aid in molecular surveillance.

The $P$. vivax merozoite surface protein 1 (PvMSP1) is a $200 \mathrm{kD}$ protein coded by a gene located on chromosome 7 [10]. It is abundant on the surface of merozoites and, during invasion, makes the first contact with human reticulocytes [11]. The carboxyl end of the $42 \mathrm{kDa}$ peptide $\left(\mathrm{PvMSP}_{42}\right)$ is processed into two segments of 33 and $19 \mathrm{kDa}$ (PvMSP1 33 and $\mathrm{PvMSP}_{19}$, respectively). PvMSP1 19 is formed by two highly conserved epidermal growth factor-like domains that bind to reticulocytes [12]. According to immunoepidemiological studies, $\mathrm{PvMSP}_{33}[13,14]$ and $\mathrm{PvMSP}_{19}$ [15-17] are highly immunogenic and, consequently, could possibly be useful as vaccine candidates for P. vivax. However, a polymorphic segment of PvMSP1 ${ }_{33}$ is presumably involved in the evasion of the host antibody response, as suggested by evidence that $\mathrm{PvMSP}_{33}$ might be under balancing selection [18-21].

In the current contribution, an analysis was made of the nucleotide and haplotype diversity of $P$. vivax $m s p 1_{42}$, considering temporal and spatial factors of samples taken from patients during the control and pre-elimination phases (1993-2007 and 2008-2011, respectively) in southern Mexico.

\section{Materials and Methods}

All subjects were informed of the nature of the study and gave their consent before being included. The protocol was conducted in accordance with the Declaration of Helsinki and was approved by the Ethics Committee of the National Institute of Public Health of Mexico (project CI1042).

The area under study is located in Jurisdiction VII of the state of Chiapas, on the Pacific side of Mexico and very close to the border with Guatemala. In this tropical area, comprising $\sim 4644 \mathrm{~km}^{2}$ and ranging from sea level to an altitude of $\sim 4000 \mathrm{~m}$, an elevated number of malaria cases were recorded in the 1990s. Subsequently, the number of cases decreased, as did the number of rural communities affected. Although in 2005 the level of infection reached a low level of 167 cases, it increased to 657 in 2006, probably due in large part to the conditions left by hurricane Stan in 2005. From 2009 on, a significant decline took place, likely because of the implementation of control measures [22]. In this Jurisdiction, malaria cases were between 1645 and 167 annually during the control phase (up to 2007), and have ranged from 657 to 101 annual cases during the pre-elimination phase (from 2008 to the present).

\subsection{Plasmodium vivax-Infected Blood Samples}

For symptomatic patients, malaria diagnoses have for many years been carried out in the laboratory facility at the Regional Center for Public Health Research (CRISP-INSP), as described previously [23]. Blood samples testing positive for P. vivax from 1993-2011 were analyzed in the current study [22,24-27]. The number of samples to study were selected 
by convenience. Since the available P. vivax-infected blood samples were few from 1993 to 2001, all of them were presently included. To reduce bias, samples from 2002 to 2011 were selected from different months of each year. A total of 116 samples, from 1993 to 2000 and 2009 to 2011, were dripped on filter paper and dried, then kept in the dark in a freezer. From 2002 to 2007, the samples were of fresh blood preserved in liquid nitrogen. In 2001 and 2008, they were comprised of both types (fresh and dried blood). Apart from the 116 dry blood samples, there were a total of 101 fresh blood samples.

\subsection{Gene Amplification and Sequencing}

Whole DNA was extracted from P. vivax-infected blood samples with the QIAamp ${ }^{\circledR}$ DNA Blood Mini kit (Qiagen, Germantown, MD, USA), as specified by the manufacturer. The gene fragment $P$. vivax pvmsp $1_{42}$ was amplified with primers: pvmsp1_42F1 5' GCCGAGGACTACGACAAAG-3' and pvmsp1_42R1 5'- CAAGCTTAGGAAGCTGGAGG$3^{\prime}$ [27]. Each PCR reaction included the following: 1X Colorless GoTaq ${ }^{\circledR}$ Flexi Buffer (Promega, Madison, WI, USA), $1 \mathrm{mM} \mathrm{MgCl}_{2}, 0.2 \mathrm{mM}$ dNTPs (Invitrogen, Carlsbad, CA, USA), $10 \mathrm{pM}$ of each primer, $1.25 \mathrm{U}_{\text {GoTaq }}{ }^{\circledR}$ DNA Polymerase (Promega, Madison, WI, USA), and 1.5-4 $\mu \mathrm{L}$ of template DNA to constitute a final volume of $50 \mu \mathrm{L}$. The PCR conditions began with denaturation at $95^{\circ} \mathrm{C}$ for $5 \mathrm{~min}$, followed by 35 cycles: denaturation at $94{ }^{\circ} \mathrm{C}$ for $60 \mathrm{~s}$, alignment at $60{ }^{\circ} \mathrm{C}$ for $60 \mathrm{~s}$, and extension at $72{ }^{\circ} \mathrm{C}$ for $7 \mathrm{~s}$. A final extension was carried out at $72{ }^{\circ} \mathrm{C}$ for $10 \mathrm{~min}$. The correct molecular size and specificity of the amplified DNA fragments were verified by electrophoresis in $1 \%$ agarose gel. For visualization, the gel with $0.2 \mu \mathrm{g} / \mathrm{mL}$ of ethidium bromide was observed under ultraviolet light in a transilluminator.

Some samples that did not amplify or gave a very low DNA concentration were re-amplified with primers pvmsp1_42F1 and pvmsp1_42R3: 5' CCCTCAAGAGGGTCAGA $3^{\prime}$ by employing the aforementioned conditions and $1-2 \mu \mathrm{L}$ of the first PCR product. All PCR reactions were performed in a T100 Thermal Cycler ${ }^{\mathrm{TM}}$ (Bio-Rad, Hercules, CA, USA).

The amplified samples displaying a single band with the correct molecular size were purified with the MinElute ${ }^{\circledR}$ PCR Purification Kit (Qiagen, Germantown, MD, USA), according to the manufacturer's instructions. The purified DNA products were sequenced by the Sanger method in Macrogen, Inc. (Geumcheon-qu, Seoul, Republic of Korea). The nucleotide sequences were reviewed manually with the BioEdit Sequencing Alignment Editor v5.0.9 [28] and aligned with Clustal W [29] by using the Sal-I sequence (GenBank: XM_001614792) as the reference. The consensus sequences were deposited in the NBCI GenBank database with the access numbers of OL411675-OL411837.

\subsection{Data Analysis}

Genetic analysis. The total number of mutations (M), segregating sites (S), and haplotypes $(\mathrm{H})$, as well as the haplotype diversity $(\mathrm{Hd})$, nucleotide diversity $(\pi)$, and genetic diversity $(\theta)$ were determined on dnaSP v5.1 software [30].

Recombination. The minimum number of recombination events detects recombination in the history of a sample [31]. The linkage disequilibrium (LD) is calculated by finding the coefficient of correlation (R) between a pair of loci, then squaring the value $\left(R^{2}\right)$ [32] These parameters were computed on the dnaSP v5.1 program (29). The range of $R^{2}$ is 0 to 1 , which indicates whether a given locus is incomplete linkage equilibrium or complete LD, respectively.

Natural selection. Natural selection was examined with two approaches. Firstly, the ratio of the fixed substitution rate between the number of substitutions of non-synonymous nucleotides $(d N)$ versus synonymous ones $(d S)$ —expressed as $d N / d S$ —was established on MEGA v6.0 software [33], utilizing the joint maximum likelihood reconstruction of ancestral states based on the Muse-Gaut [34] and Felsenstein codon substitution models [35]. Secondly, to assess the neutral theory of evolution, Tajima's D test [36] was conducted on the dnaSP v5.1 program (29). This test scrutinizes the difference between two measurements of genetic diversity: the average number of pairwise differences between nucleotides and the 
number of segregating sites. Positive values of Tajima's D suggest an excess of common variation in a region, which may be indicative of balancing selection or a contraction of the parasite population. Negative values reveal an excess of rare variations, consistent with population growth.

Haplotype networks. To determine the genealogical relationships between the $p v m s p 1_{42}$ haplotypes, haplotype changes were evaluated over time to define haplogroups, which are haplotype networks constructed with TCS v1.21 software using sequences from the entire time under study and by specific time periods [37], as reported previously [22].

Geographic assessment. To examine their geographic pattern and possible changes over time, haplotypes were mapped according to their local origin with ArcView v3 software [38].

B-cell epitopes. With the BepiPred B-cell predictor server, B-cell epitopes were predicted in $\mathrm{PvMSP}_{42}$ amino acid sequences [39], selecting the epitope prediction with $\geq 12$ consecutive amino acids and 85\% specificity: http:/ / ailab-projects1.ist.psu.edu:8080 /bcpred/ (accessed on 1 October 2021).

SplitsTree analysis. To explore the overall relationship between haplotypes in southern Mexico and worldwide, homolog sequences of $p v m s p 1_{42}$ were downloaded from NCBI (https: / / www.ncbi.nlm.nih.gov / (accessed on 7 May 2021); Table S1) [18-21,40-48]. The SplitsTree analysis was performed with the NeighborNet method on the SplitsTree v4.14.6 program [49]. This is based on haplotype networks and phylogenetic trees and allows for the construction of phylogenetic inferences. The best-fitting nucleotide substitution was GTR, revealing some invariant sites and the gamma distribution rates $(I+G)$, obtained on JModeltest2 software v2.1.10 [50]. The sequence of Plasmodium cynomolgi (GenBank: AY869723) served as an outgroup. Supplementary Table S1 shows the groups of sequences acquired from NCBI and employed in the analysis.

\section{Results}

\subsection{Pvmsp $1_{42}$ Polymorphism and Evaluation of Nucleotide and Haplotype Diversity}

The processing of 217 samples afforded $163 m s p 1_{42}$ sequences with a single nucleotide sequence and 936 base pairs (comprising nucleotides 4149-5085 or codons 1384-1695). None of the sequences were similar to the Sal-I strain (XM_001614792.1) [51]. In addition, 26 sequences exhibited double peaks in both forward and reverse pherograms (the other samples did not amplify). Pherograms with double peaks were considered to be multiple genotype infections (MGIs), because double peaks occurred at two or more nucleotide positions in the polymorphic region of $p v m s p 1_{33}$, while the $p v m s p 1_{19}$ fragment was conserved. Figure S1 illustrates the yearly distribution of the samples that did or did not amplify. Thirty-five single sequences previously reported from the same geographic region (20062007) [27] were included in the current analysis, thus constituting a total of 198 sequences. In pomsp $1_{33}, 57$ polymorphic sites and 64 mutations were identified (nucleotides 4093-4917 or codons 1364-1639), as were 7 synonymous substitutions (codons: 1476, acc $\rightarrow$ acg; 1509, gaa $\rightarrow$ gag; 1532, agt $\rightarrow$ agc; 1533, ctg $\rightarrow$ ttg; 1538, cca $\rightarrow$ ccg; 1564, gtc $\rightarrow$ gtt; and 1570, ctg $\rightarrow$ ctt) and 57 nonsynonymous substitutions (Table S2). On the other hand, pvmsp $1_{19}$ (nucleotides 4918-5085 or codons 1640-1695) was conserved and similar to the Sal-I sequence.

The nucleotide $(\pi)$ and genetic diversity $(\theta)$ of the 198 single nucleotide sequences were 0.0219 and 0.0104 , respectively. The haplotype diversity was $0.802 \pm 0.014$, finding 17 haplotypes. The most common haplotypes were h1, h4, h5, and h9, found at 31.8\%, $21.2 \%, 14.6 \%$, and $18.6 \%$, respectively. For these sequences, a minimum number of 12 recombination events was estimated, with a correlation coefficient index $\left(\mathrm{R}^{2}\right)$ of 0.332 $\left(\mathrm{LD}=\mathrm{R}^{2}\right.$; Table 1$)$. The $d N / d S$ and Tajima's $\mathrm{D}$ values for $p v m s p 1_{42}$ were positive, being 1.108 $(p>0.05)$ and $2.650(p<0.05)$, respectively (Table 1$)$. 
Table 1. Genetic parameters of P. vivax $m s p 1_{42}$ from southern Mexico, analyzed by time-periods.

\begin{tabular}{|c|c|c|c|c|c|c|c|c|c|c|c|c|c|c|}
\hline \multirow{2}{*}{$\begin{array}{l}\text { Period } \\
\text { (Years) }\end{array}$} & \multicolumn{7}{|c|}{ Genetic Diversity } & \multicolumn{3}{|c|}{ Recombination } & \multicolumn{4}{|c|}{ Natural Selection } \\
\hline & $\mathbf{N}$ & $\mathbf{M}$ & $S$ & $\mathbf{H}$ & $\begin{array}{l}\text { Hd } \\
\text { (SD) }\end{array}$ & $\begin{array}{c}\pi \\
(\mathrm{SD})\end{array}$ & $\begin{array}{c}\theta \\
(\mathrm{SD})\end{array}$ & $\mathrm{Rm}$ & $\mathbf{R}^{2}$ & $d N$ & $d S$ & $d N / d S$ & $\begin{array}{c}\text { Z-Test } \\
p \text { Value }\end{array}$ & $\begin{array}{c}\text { Tajima's } \\
\text { D }\end{array}$ \\
\hline 1993-2001 & 31 & 60 & 54 & 10 & $\begin{array}{c}0.798 \\
(0.062) \\
\end{array}$ & $\begin{array}{l}0.0196 \\
(0.002)\end{array}$ & $\begin{array}{l}0.0144 \\
(0.002)\end{array}$ & 8 & 0.350 & 38 & 6 & 0.556 & 0.290 & 0.831 \\
\hline 2002-2004 & 57 & 57 & 51 & 6 & $\begin{array}{c}0.727 \\
(0.030)\end{array}$ & $\begin{array}{l}0.0209 \\
(0.001)\end{array}$ & $\begin{array}{l}0.0118 \\
(0.001)\end{array}$ & 7 & 0.357 & 37 & 7 & 1.151 & 0.126 & 1.981 \\
\hline 2005-2007 & 54 & 61 & 54 & 12 & $\begin{array}{c}0.834 \\
(0.027)\end{array}$ & $\begin{array}{l}0.0210 \\
(0.001)\end{array}$ & $\begin{array}{l}0.0126 \\
(0.001)\end{array}$ & 10 & 0.393 & 37 & 8 & 1.282 & 0.101 & 1.810 \\
\hline 2008-2011 & 56 & 54 & 48 & 6 & $\begin{array}{c}0.697 \\
(0.041)\end{array}$ & $\begin{array}{l}0.0205 \\
(0.001)\end{array}$ & $\begin{array}{l}0.0111 \\
(0.001)\end{array}$ & 7 & 0.420 & 36 & 5 & 1.217 & 0.113 & $2.161 *$ \\
\hline Full period & 198 & 64 & 57 & 17 & $\begin{array}{c}0.802 \\
(0.014)\end{array}$ & $\begin{array}{c}0.0219 \\
(0.001)\end{array}$ & $\begin{array}{l}0.0104 \\
(0.001)\end{array}$ & 12 & 0.332 & 37 & 7 & 1.108 & 0.135 & $2.650 *$ \\
\hline
\end{tabular}

$\mathrm{N}$, number of sequences; $\mathrm{M}$, total number of mutations; $\mathrm{S}$, segregating sites; $\mathrm{H}$, number of haplotypes; Hd, haplotype diversity; $\pi$, nucleotide diversity; $\theta$, genetic diversity; Rm, minimal number of recombination events; LD, linkage disequilibrium, expressed as the $\mathrm{R}^{2}$ index; $d N$, nonsynonymous substitutions; $d S$, synonymous substitutions. ${ }^{*} p<0.05$.

\subsection{Temporal Analysis of pumsp $1_{42}$ Nucleotide Diversity, Recombination, and Natural Selection}

Of 26 multiple genotype infections encountered presently, there were $22(84.6 \%)$ in samples from the 1990s (Figure 1), and $29-75 \%$ of them in any particular year. In contrast, only one of these multiple genotype infections was discovered in the samples from 2001, two in 2009, and one in 2010. A comparison of the proportion of haplotypes was made for 2002-2011, as more than 10 single sequences were obtained per year. The proportion of the distinct haplotypes was similar in samples from 2002 and 2003. In the following years (2004-2007), however, h1 was observed in a lower proportion in those samples. The proportion of haplotypes was significantly different between samples from 2003 and 2004 (Pearson's chi-squared value $\left(\chi^{2}(5)=14.5 ; p=0.015\right)$ ) and between samples from 2006 and $2007\left(\chi^{2}(7)=16.1 ; p=0.024\right)$. H4 was detected in most of the samples in 2007. During the next four years (2008-2011), the haplotype pattern was similar to that observed in samples from 2002-2003, except for the scant number of parasites containing h9 (as in 2007). The comparison of samples from 2007 and 2008 showed a significant difference in the proportion of haplotypes $\left(\chi^{2}(4)=14.6 ; p=0.005\right.$; Figure 1$)$.

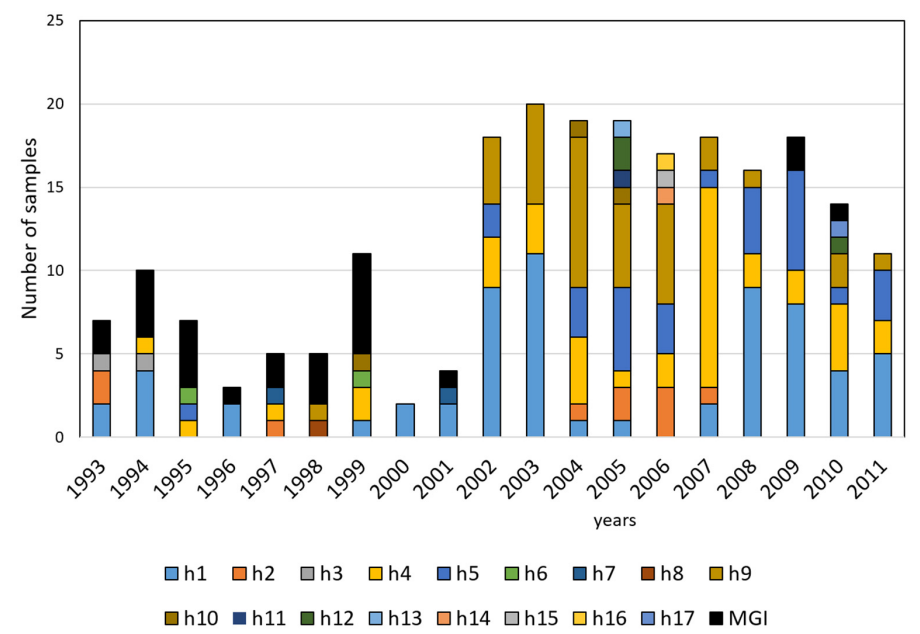

Figure 1. P. vivax $m s p 1_{42}$ haplotypes detected in samples from each year. Bars portray single sequences and multiple genotype infections (MGI) from southern Mexico. From 2002-2011, the proportion of the most common haplotypes varied over time. 
The $p v m s p 1_{42}$ sequences were grouped into four consecutive time periods. For 19932001 samples, only 31 single sequences were obtained and were considered as one group that existed during the years of highest transmission. As this group included many years and few sequences, quantitative outcomes were not analyzed or compared to the other periods, all of which involved similar number of years and more than 50 P. vivax sequences: 2002-2004 ( $n=57), 2005-2007(n=54)$, and 2008-2011 $(n=56)$. There was a subtle variation in nucleotide and genetic diversity between samples of these periods, finding $\pi$ and $\theta$ values ranging from $0.0205-0.0210$ and $0.0111-0.0126$, respectively. In contrast, the $\mathrm{R}^{2}$ index of LD increased gradually in samples from 2002-2004 to 2008-2011, and the $d N / d S$ and Tajima's D values were positive. In samples from 2008-2011, Tajima's D values were positive, although $d N / d S$ values were not significant (Table 1).

\subsection{Haplotype Network, Temporal Changes, and Haplogroups}

The haplotype network demonstrates that the $P$. vivax $m s p 1_{42}$ haplotypes of southern Mexico are separated by 1 to 75 mutational steps. When divided into four haplogroups (Hg: A, B, C, and D), they were visibly separated from each other by 17 to 20 mutational steps. Each $\mathrm{Hg}$ comprised at least one high-frequency haplotype and other closely-related low-frequency ones (Figure 2). HgA included the high-frequency haplotype h1 and three low-frequency haplotypes (h12>h6>h15) separated by two, one, and four mutational steps from $\mathrm{h} 1$, respectively. In $\mathrm{HgB}$, the high-frequency haplotype $\mathrm{h} 4$ was followed by h2 and three low-frequency haplotypes (h8, h14, and h16), separated by three, three, one, and five mutational steps from $\mathrm{h} 4$, respectively. $\mathrm{HgC}$ contained the high-frequency haplotype $\mathrm{h} 9$ and three low-frequency haplotypes (h10, h17, and h13), which were separated by four, six, and four mutational steps from h9. Haplotype h3, detected in two parasites from 1993 and 1994, was classified as $\mathrm{HgC}$ even though it was separated by 15 mutational steps from $\mathrm{h}$. $\mathrm{HgD}$ consisted of the high-frequency haplotype $\mathrm{h} 5$ and two low frequency haplotypes (h7 and h11), separated by three and four mutational steps from h5 (Figure 2). The temporal network showed that the high-frequency haplotypes from each $\mathrm{Hg}$ were encountered in sequences from all time periods, although changes in the proportion were observed in certain periods within 2002-2011. Some of the low-frequency haplotypes of each $\mathrm{Hg}$ were found in different periods (h12, h2, and h10), while others were detected in only one isolate (Figure S2).

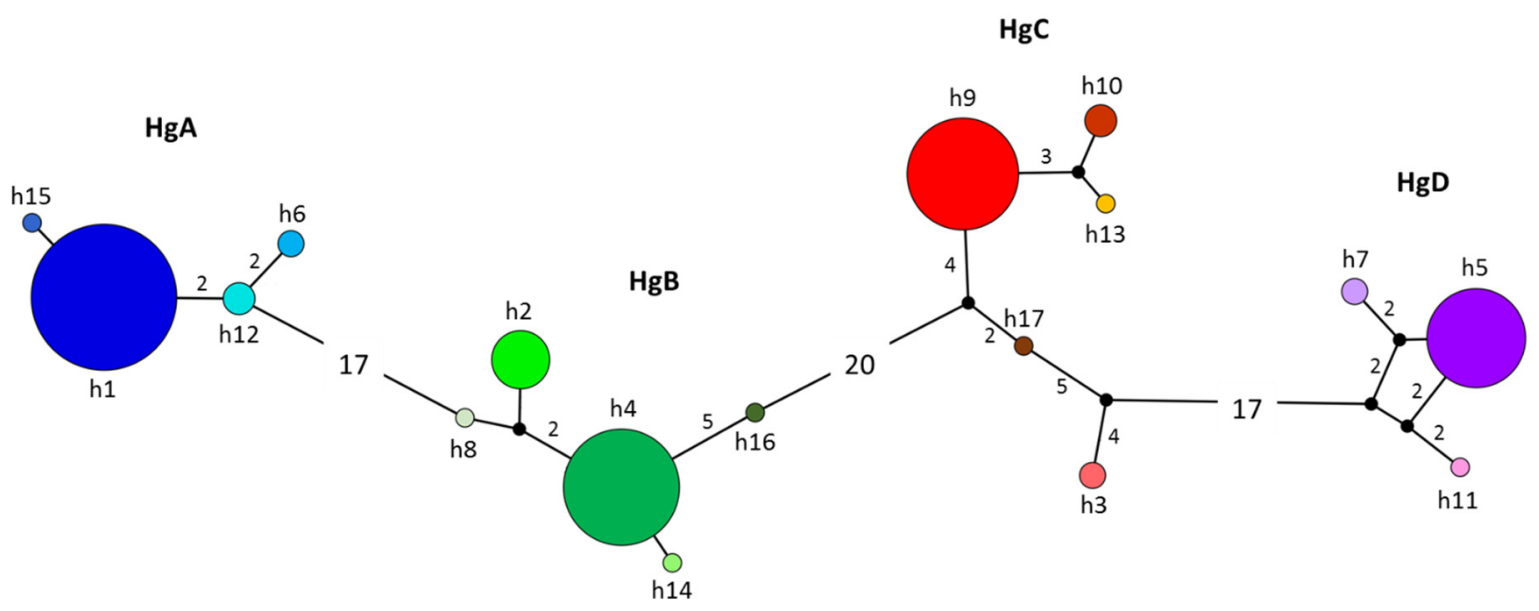

Figure 2. The haplotype network of P. vivax $m_{s p} 1_{42}$ from 1993-2011 in southern Mexico. Each color corresponds to one haplotype. The number of samples containing each haplotype is indicated by the size of the circle. Black dots represent existing or extinct haplotypes not found in the samples. The number of mutational steps between haplotypes, if higher than one, is denoted. Four haplogroups were formed ( $\mathrm{HgA}, \mathrm{HgB}, \mathrm{HgC}$, and $\mathrm{HgD})$. In the 198 sequences analyzed, haplotypes h1, h4, h5, and h9 were the most common, found at $31.8 \%, 21.2 \%, 14.6 \%$, and $18.7 \%$, respectively. Pvmsp $1_{42}$ haplotypes displayed a similar pattern of colors as in Figure 1. 


\subsection{Spatiotemporal Distribution of the Haplogroups in Southern Mexico}

The geographic pattern of haplogroups varied with time (Figure 3). Most sequences came from the municipality of Tapachula and its surrounding areas. The high-frequency haplotypes in each sample/period were detected in Tapachula City. In the 1990s, most sequences were from the city and fewer came from the outlying hilly and coastal regions. From 2002 on, most parasite sequences came from a combination of the outlying hilly areas and the city.

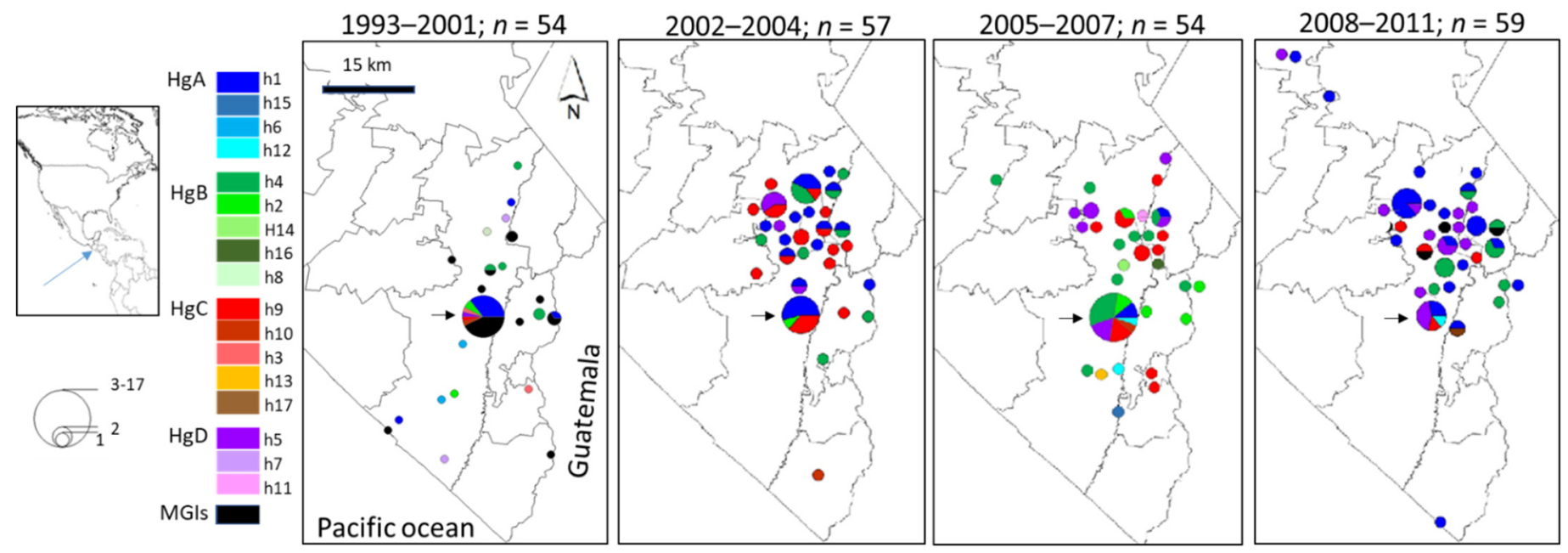

Figure 3. Geographic distribution of $\mathrm{pvmsp}_{42}$ haplotypes during four time periods from 1993-2011. The size of the circles is proportional to the number of isolates from each rural area and Tapachula City. Haplogroups are illustrated in the same colors and haplotypes in the same shades as in Figure 2. The spatial pattern of haplogroups varied from one period to another. The multiple genotype infections (MGIs) detected in 1993-2001 displayed a scattered distributed in the region. The largest circle on each map corresponds to Tapachula City (short arrow). A significant difference in the proportion of haplotypes existed when comparing samples from 2002 to 2004 and 2005 to 2007 [ $\chi^{2}(11)=27.2781$; $p=0.004]$, 2005 to 2007 and 200 to 2011 [ $\left.\chi^{2}(12)=38.4027 ; p=0.000\right]$, and 2002 to 2004 and 2008 to $2011\left[\chi^{2}(7)=18.5703 ; p=0.010\right]$.

All haplogroups and the haplotypes in each group were scattered across the geographic area (Figure 3). In 1993-2001, haplotypes of the different haplogroups were present in the city and rural areas. Members of $\mathrm{HgA}, \mathrm{HgB}, \mathrm{HgC}$, and $\mathrm{HgD}$ were found in Tapachula City in sequences from all time periods. HgA haplotypes were identified in 7 rural areas in sequences from 2002 to 2004, 4 in 2005-2007, and 18 in 2008-2011. HgB constituents were encountered in 8 rural areas in 2002-2004, 16 in 2005-2007, and 7 in 2008-2011. HgC members were evidenced in 14 rural areas in 2002-2004, 8 in 2005-2007, and 3 in 2008-2011. Lastly, h5 in HgD was discovered in 3 rural areas in 2002-2004, 6 in 2005-2007, and 10 in 2008-2011. The city was the site with the highest number of sequences. It also showed the greatest variation in the composition of each $\mathrm{Hg}$ when comparing the sequences from 2002 to 2004, 2005 to 2007, and 2008 to 2011 (Figure 3).

\subsection{Linear B-Cell Epitopes}

In the polymorphic amino acid sequences, haplogroup-specific $B$ epitopes were predicted (Figure 4). In HgA, one amino acid changed from a polar to a positive charge (Q1506R in h15). This $\mathrm{Hg}$ was similar to the Sal I sequence. In the highly variable region, the peptide SEVSQNSEKTQL in HgB and two peptides (EELKKIENEANK and NTQNEELKKIEN) in $\mathrm{HgC}$ were predicted to participate in B-cell epitopes. In HgD, the peptides IKKIGSGSTKTT and TQSMAKKAELEKY were predicted to participate in B-cell epitopes. Additionally, three peptides from the semi-conserved carboxyl region of the $33 \mathrm{kDa}$ fragment between 
codons 1668 and 1730 (EEYKKSEKKNEV, NCQLEKKEAEIT, and SKLIKENESKEI) were predicted to participate in B-cell epitopes.

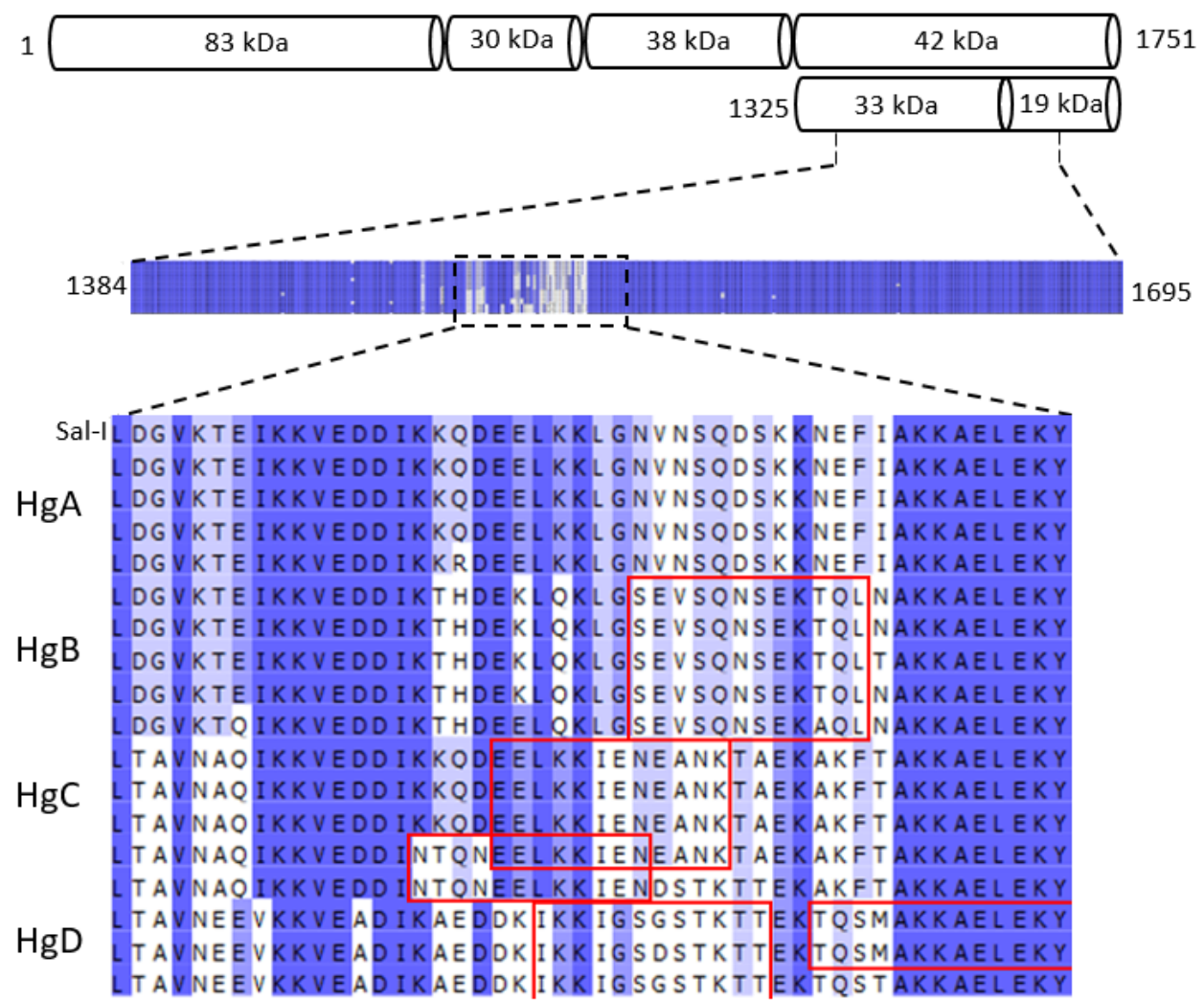

Figure 4. The P. vivax MSP1-42 kDa highly variable peptide segment (amino acids 1489-1536) and the predicted B-cell epitopes. Different B-cell epitopes were predicted for each haplogroup with the Bcpred web server (in the red boxes). The epitope prediction of $\geq 12$ consecutive amino acids was obtained by using $85 \%$ specificity. The Sal-I sequence was similar to h1 from southern Mexico.

\subsection{SplitsTree Analysis}

Pvmsp $1_{42}$ sequences from parasites in southern Mexico were compared to 631 homologous sequences from other geographic regions of the world. In 829 sequences, 117 segregating sites and 206 haplotypes were observed. The SplitsTree analysis of all haplotypes showed four main clusters with distinct assemblies and branches that contained parasites from the different parts of the world (Figure 5). Eleven of the seventeen haplotypes were exclusive to southern Mexico, including all those in $\mathrm{HgD}$. For $\mathrm{HgC}$, the high-frequency $\mathrm{h} 9$ and low-frequency h3 were exclusive to southern Mexico, whereas low-frequency h10 and h13 were shared with Nicaragua, and low-frequency h17 was detected at various sites (e.g., South Korea). HgA was closely related to the Sal-I sequence, and its high-frequency h1 was found in southern Mexico and Nicaragua, while its low-frequency haplotypes (h6, h12, and h15) were exclusive to southern Mexico. The most common haplotypes of $\mathrm{HgB}$, being high-frequency h4 and low-frequency h2, were shared with Brazil, Turkey, and South Korea. One of them was also discovered in Thailand. The low-frequency haplotypes of $\mathrm{HgB}$ (h8, h14, and h16) were exclusive to southern Mexico. Worldwide, the three most common haplotypes were identified in Asian parasites-h106 and h142 from Thailand and h77 in Sri Lanka and South Korea (Figure 5). Based on the complex network, no particular structure of the parasite population existed at the global level. Plasmodium cynomolgi was rooted in between the $\mathrm{HgC}$ and $\mathrm{HgD}$ networks (Figure 5). 


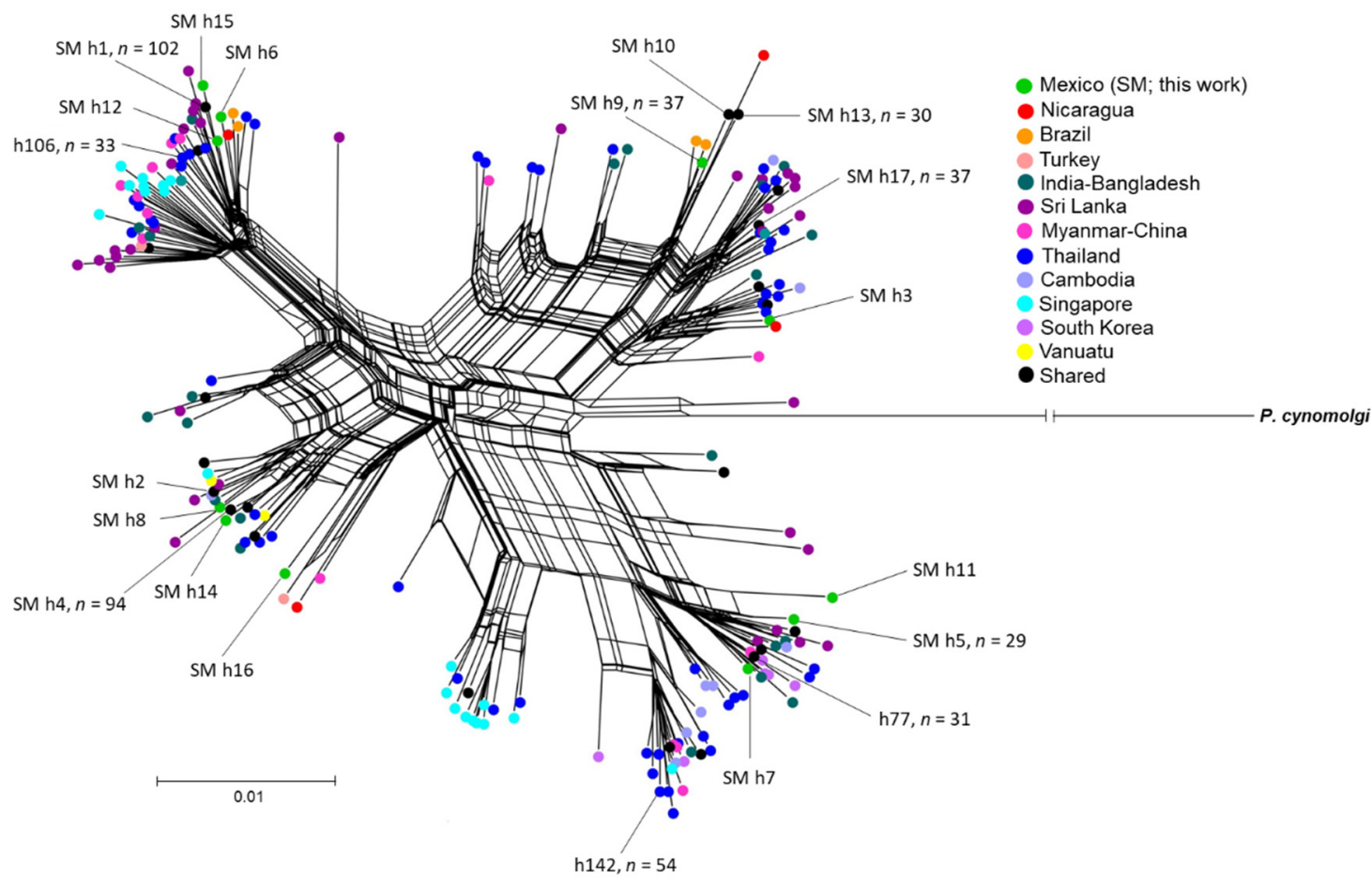

Figure 5. SplitsTree analysis of the global distribution of $P$. vivax $m s p 1_{42}$. The four main clusters found with the NeighborNet method resembled haplogroups A, B, C, and D (established by the haplotype network). Only the most common worldwide haplotypes $(\geq 29)$ and those from this study are portrayed. P. cynomolgi served as the outgroup. The bar scale denotes the nucleotide substitution per site.

\section{Discussion}

According to the genetic analysis of pvmsp $1_{42}$, the P. vivax population seems to have evolved locally, probably in Mesoamerica. The moderate level of nucleotide and haplotype diversity allowed for the evaluation of transmission dynamics during the control and pre-elimination phases (2002-2011). Despite the lower number of samples from the 1990s, the multiple genotype infections were notably high, which concurs with the high malaria transmission in those years. Although there were only subtle variations in the nucleotide and genetic diversity for $p^{0} \mathrm{msp}_{42}$, the haplotype diversity diminished and the $\mathrm{R}^{2}$ index of LD increased in samples from the pre-elimination period (samples from 2008 to 2011) compared to those periods from the control phase (samples from 2002 to 2004 and 2005 to 2007). Tajima's D value was significantly high only for the samples from 2008 to 2011.

These results indicate that $P$. vivax from southern Mexico probably underwent recombination and diversification processes, leading to the formation of several pvmsp $1_{42}$ haplogroups. Each $\mathrm{Hg}$ consisted of one high-frequency haplotype and other low-frequency ones. The current results resemble the published data obtained using microsatellites [52], the pvmsp1 segment icb5-6 [53], and pvama1 [22], as well as genomic research [54]. The highfrequency P. vivax haplotypes observed for $p v m s p 1_{42}(\mathrm{~h} 1, \mathrm{~h} 4, \mathrm{~h} 5$, and $\mathrm{h} 9$ ) represent $86.3 \%$ of the 198 single sequences (the entire sample). The four haplogroups formed for $p v m s p 1_{42}$ were detected in a dispersed pattern in the region under study, suggesting widespread circulation of the main haplotypes-likely by both human and parasite factors. For example, human activities requiring mobility across rural areas or municipalities and episodes of relapse would seem to have affected haplotype circulation. The most common haplotypes persisted over time, which must have played an important role in the similar nucleotide and genetic diversity values estimated for the different time periods.

A moderate diversity of ${ }^{2} v m s p 1_{42}$ in southern Mexico was evidenced by a previous report. The overall nucleotide diversity calculated in the current contribution (198 sequences from 1993 to 2011) is similar to that found for 35 sequences from 2006 to 2007 [27]. 
This might be due to hurricane Stan, which created conditions favoring the transmission of endemic and relapsing P. vivax haplotypes in the years immediately after 2005 [55]. A greater number of low-frequency haplotypes were identified when the number of $P$. vivax cases was higher. In the low endemic area of southern Mexico, the presence of multiple genotype infections in the human host may have favored the recombination of different parasite haplotypes in the mosquito vector [56,57]. However, the vector specificity previously observed in the region could have restricted recombination for certain parasite haplotypes $[52,58]$. The number of isolates exhibiting $p o m s p 1_{42}$ single sequences in the 1990s was low, perhaps impeded by the detection of other low-frequency alleles. This issue cannot be resolved in the current study. Importantly, the analysis of pvama1 $1_{I I}$ in infected blood samples from the 1990s showed multiple genotype infections consisting of high- and low-frequency haplotypes [22].

The $\mathrm{R}^{2}$ index of LD and Tajima's $\mathrm{D}$ values rose as transmission decreased, suggesting a contraction in the parasite population during the years of the pre-elimination phase (2008-2011). Not only are these results congruent with previous findings using Pvama1 $_{\text {II }}$ [22], but they are also supported by the lack of malaria outbreaks after 2007, as well as the sensitivity of $P$. vivax to treatment based on chloroquine and primaquine [59]. The comparison of 2004 and 2013-2015 in a highly endemic region of Myanmar, contrarily, revealed a reduction in the number of malaria cases, a variation in the frequency of genetic clusters of pomsp1-icb5-6, and an increase in the number of haplotypes and the values for recombination events [60]. Although Myanmar has set a target date of 2030 for the elimination of malaria, it faces a complex scenario of haplotype diversity and drug-resistance.

Malaria transmission in southern Mexico underwent a slow decline in the 1990s, reflected in a lower number of malaria cases. Since the year 2000, this decrease has continued as a result of intensive vector control campaigns, the active detection of malaria cases, and the administration of chloroquine and primaquine treatment schemes [2]. During the sample collection, the treatment for $P$. vivax involved monthly and intermittent single doses of chloroquine and primaquine. It was estimated that about $50 \%$ of the patients had at least one relapse of malaria [59]. Under that scenario, endemic/relapsing haplotypes became highly adapted and persisted overtime.

No differences existed in nucleotide and genetic diversity between the sequences from control periods (2002-2004 and 2005-2007) and the sequences from the pre-elimination period (2008-2011). However, variation in the proportion of some haplotypes and haplogroups was evident from one year to another. Although immunogenicity and natural antibody responses against $\mathrm{PvMSP}_{19}[61,62]$ and $\mathrm{PvMSP}_{42}[13,63]$ have been reported in P. vivax-infected patients. The PvMSP1 $1_{33}$ fragment, on the other hand, is highly variable compared to PvMSP1 19 [18-21,43,44,64], and is presumably involved in the evasion of the immune responses [19]. Temporal changes in the proportion of the haplogroups might have been the result of balancing selection acting on the polymorphic fragment $\mathrm{PvMSP}_{33}$, an idea supported by the excess of non-synonymous mutations and positive $d N / d S$ values.

Additionally, the four haplogroups are different from the B-cell epitopes predicted by the BepiPred program. Under these conditions, haplogroup- or haplotype-specific antibody responses may be generated in the host and contribute to the "immature" natural responses, as proposed by Wickramarachchi et al. [14]. In low-transmission regions, the half-life of the immune response following a P. vivax infection is suggested to be less than six months $[27,62]$. In the absence of frequent blood infections, therefore, immunity to the blood stages of the parasite becomes deficient during the transmission season. In one study, some immune serum samples from patients were reactive to only one of the two haplotypes of $\mathrm{PvMSP}_{33}$ (the Sal-I and Belem strains) [63]. Further research at the community level might be necessary to decipher whether or not antibody responses against distinct PvMSP1 33 immunotypes can cause haplotype rotation in hypo-endemic settings. Otherwise, genetic drift could have contributed to haplotype or haplogroup fluctuations over time. Many pomsp $1_{42}$ haplotypes were exclusive to southern Mexico or Mesoamerica, 
which indicates that this gene fragment might be instrumental in distinguishing native $P$. vivax strains from those introduced from other regions.

\section{Conclusions}

Pvmsp $1_{42}$ was adequate to estimate genetic changes in sequences from the control and pre-elimination phases. Unlike samples from the control phase, those from the preelimination period were characterized by an insignificant rate of multiple genotype infections, a reduction in haplotype diversity, and an increase in LD and Tajima's D valuesindicative of a contraction in the parasite population. All four haplogroups of the present study exhibited specific B-cell epitopes, and all displayed a scattered pattern of dispersion in the region, with some fluctuations over time. The results suggest that the elimination of the malaria parasite will require the maintenance of malaria cases at a low level until transmission is interrupted. $\mathrm{PvMSP}_{42}$ is a good candidate for molecular surveillance to evaluate anti-malaria programs. Further research is indispensable to elucidate whether or not the presumed fluctuations of the haplogroups in $\mathrm{PvMSP}_{42}$ were due to immune evasion.

Supplementary Materials: Figures S1 and S2 and Tables S1 and S2 are available online at: https: / www.mdpi.com/article/10.3390/microorganisms10010186/s1, accessed on 5 January 2022. Figure S1: P. vivax samples from southern Mexico, 1993-2011. Figure S2: Temporal haplotype distribution of Plasmodium vivax pvmsp $1_{42}$ in southern Mexico. Table S1: Origin and accession numbers of the pvmsp $1_{42}$ sequences obtained from NCBI at https: / /www.ncbi.nlm.nih.gov/. Table S2: Haplotypes and amino acid substitutions for PvMSP1 $1_{42} \mathrm{kDa}$ parasites in southern Mexico.

Author Contributions: Conceptualization, L.G.-C. and R.C.; Formal analysis, A.F.-A., L.G.-C. and F.S.-V.; Funding acquisition, L.G.-C. and R.C.; Methodology, A.F.-A., F.S.-V. and M.A.S.-B.; Resources, L.G.-C. and C.X.; Supervision, L.G.-C., C.X. and R.C.; Validation, A.F.-A. and F.S.-V.; Writing-original draft, A.F.-A. and C.X.; Writing-review and editing, L.G.-C. and R.C. All authors have read and agreed to the published version of the manuscript.

Funding: The current research was funded by CONACyT-Mexico, grant number CB-01-131247.

Institutional Review Board Statement: Not applicable.

Informed Consent Statement: Not applicable.

Data Availability Statement: All relevant data is contained within the article or Supplementary Materials.

Acknowledgments: This work is part of the doctoral thesis of Alejandro Flores-Alanis, former student at the Programa de Doctorado en Ciencias Biomédicas, Universidad Nacional Autónoma de México (UNAM). He received fellowship 347268 from CONACYT-Mexico.

Conflicts of Interest: The authors declare that they have no conflict of interest. The funders had no role in the design of the study, in the collection, analyses, or interpretation of data, in the writing of the manuscript, or in the decision to publish the results.

\section{References}

1. WHO. World Malaria Report 2021; WHO: Geneva, Switzerland, 2021. Available online: https://www.who.int/teams/globalmalaria-programme/reports/world-malaria-report-2021 (accessed on 16 December 2021).

2. WHO. Global Malaria Control and Elimination: Report of a Technical Review; WHO: Geneva, Switzerland, 2008. Available online: https: //www.who.int/publications/i/item/9789241596756https://www.who.int/publications/i/item/9789241596756 (accessed on 16 December 2021).

3. Dirección General de Epidemiología. Boletín Epidemiológico 1995-2018; Secretaria de Salud: Mexico City, México, 2018. Available online: https:/ / www.gob.mx/salud/acciones-y-programas/historico-boletin-epidemiologico (accessed on 16 December 2021).

4. Pan American Health Organization. Epidemiological Update. Increase of Malaria in the Americas, 2018; PAHO: Washington, DC, USA, 2018. Available online: https:/ /www.paho.org/hq/index.php?option=com_docman\&view=download\&category_slug=2018-9 581\&alias=43434-30-january-2018-malaria-epidemiological-update-434\&Itemid=270\&lang=en (accessed on 16 December 2021).

5. Neafsey, D.E.; Galinsky, K.; Jiang, R.H.; Young, L.; Sykes, S.M.; Saif, S.; Gujja, S.; Goldberg, J.M.; Young, S.; Zeng, Q.; et al. The malaria parasite Plasmodium vivax exhibits greater genetic diversity than Plasmodium falciparum. Nat. Genet. 2012, 44, 1046-1050. [CrossRef] [PubMed] 
6. Ekland, E.H.; Fidock, D.A. Advances in understanding the genetic basis of antimalarial drug resistance. Curr. Opin. Microbiol. 2007, 10, 363-370. [CrossRef]

7. Barry, A.E.; Arnott, A. Strategies for designing and monitoring malaria vaccines targeting diverse antigens. Front. Immunol. 2014, 5, 359. [CrossRef] [PubMed]

8. Barry, A.E.; Waltmann, A.; Koepfli, C.; Barnadas, C.; Mueller, I. Uncovering the transmission dynamics of Plasmodium vivax using population genetics. Pathog. Glob. Health 2015, 109, 142-152. [CrossRef]

9. Volkman, S.K.; Neafsey, D.E.; Schaffner, S.F.; Park, D.J.; Wirth, D.F. Harnessing genomics and genome biology to understand malaria biology. Nat. Rev. Genet. 2012, 13, 315-328. [CrossRef] [PubMed]

10. del Portillo, H.A.; Longacre, S.; Khouri, E.; David, P.H. Primary structure of the merozoite surface antigen 1 of Plasmodium vivax reveals sequences conserved between different Plasmodium species. Proc. Natl. Acad. Sci. USA 1991, 88, 4030-4034. [CrossRef]

11. Wright, G.J.; Rayner, J.C. Plasmodium falciparum erythrocyte invasion: Combining function with immune evasion. PLoS Pathog. 2014, 10, e1003943. [CrossRef]

12. Han, E.T.; Song, T.E.; Park, J.H.; Shin, E.H.; Guk, S.M.; Kim, T.Y.; Chai, J.Y. Allelic dimorphism in the merozoite surface protein-3alpha in Korean isolates of Plasmodium vivax. Am. J. Trop. Med. Hyg. 2004, 71, 745-749. [CrossRef]

13. Sachdeva, S.; Ahmad, G.; Malhotra, P.; Mukherjee, P.; Chauhan, V.S. Comparison of immunogenicities of recombinant Plasmodium vivax merozoite surface protein 1 19- and 42-kiloDalton fragments expressed in Escherichia coli. Infect. Immun. 2004, 72, 5775-5782. [CrossRef]

14. Wickramarachchi, T.; Illeperuma, R.J.; Perera, L.; Bandara, S.; Holm, I.; Longacre, S.; Handunnetti, S.M.; Udagama-Randeniya, P.V. Comparison of naturally acquired antibody responses against the C-terminal processing products of Plasmodium vivax Merozoite Surface Protein-1 under low transmission and unstable malaria conditions in Sri Lanka. Int. J. Parasitol. 2007, 37, 199-208. [CrossRef]

15. Riccio, E.K.; Totino, P.R.; Pratt-Riccio, L.R.; Ennes-Vidal, V.; Soares, I.S.; Rodrigues, M.M.; de Souza, J.M.; Daniel-Ribeiro, C.T.; Ferreira-da-Cruz Mde, F. Cellular and humoral immune responses against the Plasmodium vivax MSP-1(1)(9) malaria vaccine candidate in individuals living in an endemic area in north-eastern Amazon region of Brazil. Malar. J. 2013, 12, 326. [CrossRef] [PubMed]

16. Wang, Q.; Zhao, Z.; Zhang, X.; Li, X.; Zhu, M.; Li, P.; Yang, Z.; Wang, Y.; Yan, G.; Shang, H.; et al. Naturally Acquired Antibody Responses to Plasmodium vivax and Plasmodium falciparum Merozoite Surface Protein 1 (MSP1) C-Terminal 19 kDa Domains in an Area of Unstable Malaria Transmission in Southeast Asia. PLoS ONE 2016, 11, e0151900. [CrossRef] [PubMed]

17. Punnath, K.; Dayanand, K.K.; Midya, V.; Chandrashekar, V.N.; Achur, R.N.; Kakkilaya, S.B.; Ghosh, S.K.; Kumari, S.N.; Gowda, D.C. Acquired antibody responses against merozoite surface protein-119 antigen during Plasmodium falciparum and P. vivax infections in South Indian city of Mangaluru. J. Parasit. Dis. 2020, 45, 1-15. [CrossRef]

18. Kang, J.-M.; Ju, H.-L.; Kang, Y.-M.; Lee, D.-H.; Moon, S.-U.; Sohn, W.-M.; Park, J.-W.; Kim, T.-S.; Na, B.-K. Genetic polymorphism and natural selection in the C-terminal $42 \mathrm{kDa}$ region of merozoite surface protein-1 among Plasmodium vivax Korean isolates. Malar. J. 2012, 11, 206. [CrossRef]

19. Dias, S.; Longacre, S.; Escalante, A.A.; Udagama-Randeniya, P.V. Genetic diversity and recombination at the C-terminal fragment of the merozoite surface protein-1 of Plasmodium vivax (PvMSP-1) in Sri Lanka. Infect. Genet. Evol. 2011, 11, 145-156. [CrossRef] [PubMed]

20. Parobek, C.M.; Bailey, J.A.; Hathaway, N.J.; Socheat, D.; Rogers, W.O.; Juliano, J.J. Differing Patterns of Selection and Geospatial Genetic Diversity within Two Leading Plasmodium vivax Candidate Vaccine Antigens. PLoS Negl. Trop. Dis. 2014, 8, e2796. [CrossRef] [PubMed]

21. Zhou, X.; Tambo, E.; Su, J.; Fang, Q.; Ruan, W.; Chen, J.H.; Yin, M.B.; Zhou, X.N. Genetic Diversity and Natural Selection in 42 kDa Region of Plasmodium vivax Merozoite Surface Protein-1 from China-Myanmar Endemic Border. Korean J. Parasitol. 2017, 55, 473-480. [CrossRef] [PubMed]

22. Flores-Alanis, A.; Gonzalez-Ceron, L.; Santillan, F.; Ximenez, C.; Sandoval, M.A.; Cerritos, R. Temporal genetic changes in Plasmodium vivax apical membrane antigen 1 over 19 years of transmission in southern Mexico. Parasit Vectors 2017, $10,217$. [CrossRef] [PubMed]

23. Gonzalez-Ceron, L.; Rodriguez, M.H.; Betanzos, A.F.; Abadia, A. Efficacy of a rapid test to diagnose Plasmodium vivax in symptomatic patients of Chiapas, Mexico. Salud Publica Mex. 2005, 47, 282-287. [PubMed]

24. Gonzalez-Ceron, L.; Rodriguez, M.H.; Wirtz, R.A.; Sina, B.J.; Palomeque, O.L.; Nettel, J.A.; Tsutsumi, V. Plasmodium vivax: A monoclonal antibody recognizes a circumsporozoite protein precursor on the sporozoite surface. Exp. Parasitol. 1998, 90, 203-211. [CrossRef] [PubMed]

25. Rodriguez, M.H.; Gonzalez-Ceron, L.; Hernandez, J.E.; Nettel, J.A.; Villarreal, C.; Kain, K.C.; Wirtz, R.A. Different prevalences of Plasmodium vivax phenotypes VK210 and VK247 associated with the distribution of Anopheles albimanus and Anopheles pseudopunctipennis in Mexico. Am. J. Trop. Med. Hyg. 2000, 62, 122-127. [CrossRef] [PubMed]

26. Gonzalez-Ceron, L.; Martinez-Barnetche, J.; Montero-Solis, C.; Santillan, F.; Soto, A.M.; Rodriguez, M.H.; Espinosa, B.J.; Chavez, O.A. Molecular epidemiology of Plasmodium vivax in Latin America: Polymorphism and evolutionary relationships of the circumsporozoite gene. Malar. J. 2013, 12, 243. [CrossRef] [PubMed]

27. Gonzalez-Ceron, L.; Cerritos, R.; Corzo-Mancilla, J.; Santillan, F. Diversity and evolutionary genetics of the three major Plasmodium vivax merozoite genes participating in reticulocyte invasion in southern Mexico. Parasit Vectors 2015, 8, 651. [CrossRef] [PubMed] 
28. Hall, T.A. BioEdit: A user-friendly biological sequence alignment editor and analysis program for Windows 95/98/NT. Nucl. Acids. Symp. Ser. 1999, 41, 95-98.

29. Thompson, J.D.; Higgins, D.G.; Gibson, T.J. CLUSTAL W: Improving the sensitivity of progressive multiple sequence alignment through sequence weighting, position-specific gap penalties and weight matrix choice. Nucleic Acids Res. 1994, 22, 4673-4680. [CrossRef] [PubMed]

30. Librado, P.; Rozas, J. DnaSP v5: A software for comprehensive analysis of DNA polymorphism data. Bioinformatics 2009, 25, 1451-1452. [CrossRef]

31. Hudson, R.R.; Kaplan, N.L. Statistical properties of the number of recombination events in the history of a sample of DNA sequences. Genetics 1985, 111, 147-164. [CrossRef]

32. Hill, W.G.; Robertson, A. Linkage disequilibrium in finite populations. Theor. Appl. Genet. 1968, 38, 226-231. [CrossRef]

33. Tamura, K.; Stecher, G.; Peterson, D.; Filipski, A.; Kumar, S. MEGA6: Molecular Evolutionary Genetics Analysis Version 6.0. Mol. Biol. Evol. 2013, 30, 2725-2729. [CrossRef]

34. Muse, S.V.; Gaut, B.S. A likelihood approach for comparing synonymous and nonsynonymous nucleotide substitution rates, with application to the chloroplast genome. Mol. Biol. Evol. 1994, 11, 715-724. [CrossRef]

35. Felsenstein, J. Evolutionary trees from DNA sequences: A maximum likelihood approach. J. Mol. Evol. 1981, 17, 368-376. [CrossRef] [PubMed]

36. Tajima, F. Statistical method for testing the neutral mutation hypothesis by DNA polymorphism. Genetics 1989, 123, 585-595. [CrossRef] [PubMed]

37. Clement, M.; Posada, D.; Crandall, K.A. TCS: A computer program to estimate gene genealogies. Mol. Ecol. 2000, 9, 1657-1659. [CrossRef] [PubMed]

38. Lee, J.; Wang, D.W.S. Statistical Analysis with ArcView GIS; John Wiley: New York, NY, USA, 2001.

39. El-Manzalawy, Y.; Dobbs, D.; Honavar, V. Predicting linear B-cell epitopes using string kernels. J. Mol. Recognit. 2008, 21, 243-255. [CrossRef]

40. Gutierrez, S.; Gonzalez-Ceron, L.; Montoya, A.; Sandoval, M.A.; Torres, M.E.; Cerritos, R. Genetic structure of Plasmodium vivax in Nicaragua, a country in the control phase, based on the carboxyl terminal region of the merozoite surface protein-1. Infect. Genet. Evol. 2016, 40, 324-330. [CrossRef]

41. Putaporntip, C.; Jongwutiwes, S.; Sakihama, N.; Ferreira, M.U.; Kho, W.G.; Kaneko, A.; Kanbara, H.; Hattori, T.; Tanabe, K. Mosaic organization and heterogeneity in frequency of allelic recombination of the Plasmodium vivax merozoite surface protein-1 locus. Proc. Natl. Acad. Sci. USA 2002, 99, 16348-16353. [CrossRef]

42. Putaporntip, C.; Jongwutiwes, S.; Seethamchai, S.; Kanbara, H.; Tanabe, K. Intragenic recombination in the $3^{\prime}$ portion of the merozoite surface protein 1 gene of Plasmodium vivax. Mol. Biochem. Parasitol. 2000, 109, 111-119. [CrossRef]

43. Zeyrek, F.Y.; Tachibana, S.-I.; Yuksel, F.; Doni, N.; Palacpac, N.; Arisue, N.; Horii, T.; Coban, C.; Tanabe, K. Limited Polymorphism of the Plasmodium vivax Merozoite Surface Protein 1 Gene in Isolates from Turkey. Am. J. Trop. Med. Hyg. 2010, 83, $1230-1237$. [CrossRef]

44. Thakur, A.; Alam, M.T.; Sharma, Y.D. Genetic diversity in the C-terminal 42kDa region of merozoite surface protein-1 of Plasmodium vivax (PvMSP-1(42)) among Indian isolates. Acta Trop. 2008, 108, 58-63. [CrossRef]

45. Sheikh, I.H.; Kaushal, D.C.; Singh, V.; Kumar, N.; Chandra, D.; Kaushal, N.A. Cloning, overexpression and characterization of soluble 42kDa fragment of merozoite surface protein-1 of Plasmodium vivax. Protein Expr. Purif. 2014, 103, 64-74. [CrossRef]

46. Jongwutiwes, S.; Putaporntip, C.; Hughes, A.L. Bottleneck effects on vaccine-candidate antigen diversity of malaria parasites in Thailand. Vaccine 2010, 28, 3112-3117. [CrossRef]

47. Ng, L.C.; Lee, K.S.; Tan, C.H.; Ooi, P.L.; Lam-Phua, S.G.; Lin, R.; Pang, S.C.; Lai, Y.L.; Solhan, S.; Chan, P.P.; et al. Entomologic and molecular investigation into Plasmodium vivax transmission in Singapore, 2009. Malar. J. 2010, 9, 305. [CrossRef]

48. Han, E.-T.; Wang, Y.; Lim, C.S.; Cho, J.H.; Chai, J.-Y. Genetic diversity of the malaria vacine candidate merozoite surface protein 1 gene of Plasmodium vivax field isolates in Republic of Korea. Parasitol. Res. 2011, 109, 1571-1576. [CrossRef] [PubMed]

49. Huson, D.H.; Bryant, D. Application of phylogenetic networks in evolutionary studies. Mol. Biol. Evol. 2006, $23,254-267$. [CrossRef] [PubMed]

50. Darriba, D.; Taboada, G.L.; Doallo, R.; Posada, D. jModelTest 2: More models, new heuristics and parallel computing. Nat. Methods 2012, 9, 772. [CrossRef] [PubMed]

51. Carlton, J.M.; Adams, J.H.; Silva, J.C.; Bidwell, S.L.; Lorenzi, H.; Caler, E.; Crabtree, J.; Angiuoli, S.V.; Merino, E.F.; Amedeo, P.; et al. Comparative genomics of the neglected human malaria parasite Plasmodium vivax. Nature 2008, 455, 757-763. [CrossRef]

52. Joy, D.A.; Gonzalez-Ceron, L.; Carlton, J.M.; Gueye, A.; Fay, M.; McCutchan, T.F.; Su, X.Z. Local adaptation and vector-mediated population structure in Plasmodium vivax malaria. Mol. Biol. Evol. 2008, 25, 1245-1252. [CrossRef]

53. Cerritos, R.; Gonzalez-Ceron, L.; Nettel, J.A.; Wegier, A. Genetic structure of Plasmodium vivax using the merozoite surface protein 1 icb5-6 fragment reveals new hybrid haplotypes in southern Mexico. Malar. J. 2014, 13, 35. [CrossRef]

54. Hupalo, D.N.; Luo, Z.; Melnikov, A.; Sutton, P.L.; Rogov, P.; Escalante, A.; Vallejo, A.F.; Herrera, S.; Arevalo-Herrera, M.; Fan, Q.; et al. Population genomics studies identify signatures of global dispersal and drug resistance in Plasmodium vivax. Nat. Genet. 2016, 48, 953-958. [CrossRef] 
55. Gonzalez-Ceron, L.; Mu, J.; Santillan, F.; Joy, D.; Sandoval, M.A.; Camas, G.; Su, X.; Choy, E.V.; Torreblanca, R. Molecular and epidemiological characterization of Plasmodium vivax recurrent infections in southern Mexico. Parasit Vectors 2013, 6, 109. [CrossRef]

56. Bousema, T.; Drakeley, C. Epidemiology and infectivity of Plasmodium falciparum and Plasmodium vivax gametocytes in relation to malaria control and elimination. Clin. Microbiol. Rev. 2011, 24, 377-410. [CrossRef] [PubMed]

57. Ferreira, M.U.; Karunaweera, N.D.; da Silva-Nunes, M.; da Silva, N.S.; Wirth, D.F.; Hartl, D.L. Population structure and transmission dynamics of Plasmodium vivax in rural Amazonia. J. Infect. Dis. 2007, 195, 1218-1226. [CrossRef] [PubMed]

58. González-Cerón, L.; Rodríguez, M.H.; Ovilla-Muñoz, M.T.; Santillán-Valenzuela, F.; Hernández-Ávila, J.E.; Rodríguez, M.C.; Martínez-Barnetche, J.; Villarreal-Treviño, C. Ookinete-Specific Genes and 18S SSU rRNA Evidenced in Plasmodium vivax Selection and Adaptation by Sympatric Vectors. Front. Genet. 2020, 10, 1362. [CrossRef]

59. Gonzalez-Ceron, L.; Rodriguez, M.H.; Sandoval, M.A.; Santillan, F.; Galindo-Virgen, S.; Betanzos, A.F.; Rosales, A.F.; Palomeque, O.L. Effectiveness of combined chloroquine and primaquine treatment in 14 days versus intermittent single dose regimen, in an open, non-randomized, clinical trial, to eliminate Plasmodium vivax in southern Mexico. Malar. J. 2015, 14, 426. [CrossRef] [PubMed]

60. Naw, H.; Kang, J.M.; Moe, M.; Lee, J.; Le, H.G.; Vo, T.C.; Mya, Y.Y.; Myint, M.K.; Htun, Z.T.; Kim, T.S.; et al. Temporal Changes in the Genetic Diversity of Plasmodium vivax Merozoite Surface Protein-1 in Myanmar. Pathogens 2021, 10, 916. [CrossRef] [PubMed]

61. Zeyrek, F.Y.; Babaoglu, A.; Demirel, S.; Erdogan, D.D.; Ak, M.; Korkmaz, M.; Coban, C. Analysis of Naturally Acquired Antibody Responses to the 19-kd C-Terminal Region of Merozoite Surface Protein-1 of Plasmodium vivax from Individuals in Sanliurfa, Turkey. Am. J. Trop. Med. Hyg. 2008, 78, 729-732. [CrossRef]

62. Longley, R.J.; White, M.T.; Takashima, E.; Morita, M.; Kanoi, B.N.; Li Wai Suen, C.S.N.; Betuela, I.; Kuehn, A.; Sripoorote, P.; Franca, C.T.; et al. Naturally acquired antibody responses to more than 300 Plasmodium vivax proteins in three geographic regions. PLoS Negl. Trop. Dis. 2017, 11, e0005888. [CrossRef]

63. Dinzouna-Boutamba, S.D.; Lee, S.; Son, U.H.; Song, S.M.; Yun, H.S.; Joo, S.Y.; Kwak, D.; Rhee, M.H.; Chung, D.I.; Hong, Y.; et al. Distribution of Antibodies Specific to the 19-kDa and 33-kDa Fragments of Plasmodium vivax Merozoite Surface Protein 1 in Two Pathogenic Strains Infecting Korean Vivax Malaria Patients. Osong Public Health Res. Perspect. 2016, 7, 213-219. [CrossRef]

64. Murhandarwati, E.E.H.; Herningtyas, E.H.; Puspawati, P.; Mau, F.; Chen, S.B.; Shen, H.M.; Chen, J.H. Genetic diversity of Merozoite surface protein 1-42 (MSP1-42) fragment of Plasmodium vivax from Indonesian isolates: Rationale implementation of candidate MSP1 vaccine. Infect. Genet. Evol. 2020, 85, 104573. [CrossRef] 